\title{
CORRIGENDUM
}

\section{A small-amplitude study of solitons near critical plasma compositions - CORRIGENDUM}

\author{
C. P. Olivier, F. Verheest and S. K. Maharaj \\ doi:10.1017/S0022377816001082, Published by Cambridge University Press, \\ 28 November 2016
}

The expression of Poisson's equation (2.1) on page 4 is incorrect. The equation should read:

$$
\frac{\partial^{2} \phi}{\partial x^{2}}+\sum_{j=1}^{N} Z_{j} n_{j}=0
$$

\section{REFERENCE}

Olivier, C. P., Verheest, F. \& Maharaj, S. K. 2016 A small-amplitude study of solitons near critical plasma compositions. J. Plasma Phys. 82, 905820605. 